DOI: 10.12957/demetra.2016.22194

\title{
Corpo, sexualidade, gênero e mediações culturais em revistas femininas juvenis: questões para a saúde sexual e reprodutiva
}

\section{Body, sexuality, gender and cultural mediations in young women's magazines: issues on sexual and reproductive health}

\author{
Bartira dos Reis Rocha Cezar ${ }^{\mathrm{r}}$ \\ Eliane Portes Vargas' \\ ${ }^{1}$ Fundação Oswaldo Cruz-FIOCRUZ, Instituto \\ Oswaldo Cruz. Rio de Janeiro-RJ, Brasil. \\ Correspondência / Correspondence \\ Bartira dos Reis Rocha Cezar \\ Fundação Oswaldo Cruz-Fiocruz - Instituto \\ Oswaldo Cruz. Av. Brasil, 4365 CEP 21045 \\ 900, Rio de Janeiro-RJ, Brasil. \\ E-mail:bartirarrcezar@gmail.com
}

\section{Resumo}

As ações de atenção à saúde sexual e reprodutiva têm exigido constante diálogo entre a escola e os serviços de saúde. O incremento de ações desta natureza requer o aprimoramento das abordagens interdisciplinares e o desenvolvimento de metodologias adequadas para a educação voltada aos jovens envolvendo a sexualidade, seja no âmbito escolar ou através dos serviços de saúde. Este estudo de cunho etnográfico orienta-se pelas perspectivas antropológica e sociológica, agregando os aportes teóricos dos Estudos de Recepção do campo da Comunicação Social. Por meio da conjugação dessas perspectivas, foi realizada uma análise das concepções de corpo e sexualidade, a partir das percepções críticas atribuídas às revistas femininas juvenis Capricho e Atrevida, entre jovens escolares de 12 a 16 anos, em uma escola pública da Baixada Fluminense, Rio de Janeiro. Compreendendo as revistas como mediações culturais no processo comunicativo/educativo, as relações de gênero implicadas nas concepções sobre práticas preventivas e sexuais também foram consideradas. Uma maior compreensão das lógicas norteadoras das concepções entre os jovens é relevante para a formulação de políticas públicas em saúde e educação. Os resultados indicam a pertinência das reflexões produzidas nas atividades críticas e reflexivas envolvendo produtos culturais, e suas respectivas metodologias de aplicação, em práticas educativas nos campos da saúde e das biociências, em suas vertentes de ensino formal e não formal. $\mathrm{O}$ uso contextualizado das revistas entre os jovens indicou sua potencialidade na análise das mediações culturais e nas discussões ampliadas sobre saúde sexual e reprodutiva entre jovens mediante sua experimentação de entrada na sexualidade.

Palavras-chave: Gênero. Sexualidade. Saúde Reprodutiva. Mediações Culturais. 


\section{Abstract}

Actions on sexual and reproductive health care have required a constant dialogue between schools and health services. The increase in the number of actions of this nature requires improvement of interdisciplinary approaches and the development of appropriate methodologies for education aimed at youngsters involving sexuality, whether in the school environment or through health services. This ethnographic study is guided by anthropological and sociological perspectives that aggregate theoretical contributions of Reception Studies in the field of Social Communication. Through the combination of these perspectives, an analysis of the concepts of body and sexuality has been carried out, stemming from the critical perceptions attributed to two young women's magazines, "Capricho" and "Atrevida", among schoolchildren from 12 to 16 years old in a public school at Baixada Fluminense-RJ. Acknowledging magazines as cultural mediations in the communication / education process, gender relations involved in conceptions about preventive and sexual practices have also been considered. A greater understanding of the guiding logic of conceptions among youngsters has shown to be relevant to the formulation of public policies concerning health and education. The results indicate the relevance of these reflections produced in the critical and reflective activities involving cultural products and their application methodologies in educational practices within the field of health and biosciences, regarding formal and non-formal teaching. The contextualized use of such magazines with youngsters has indicated its potential in the analysis of cultural mediations and in expanded discussions on sexual and reproductive health among youngsters upon their initial experimentation on sexuality.

Key words: Gender. Sexuality. Reproductive Health. Cultural Mediations.

\section{Introdução}

A atenção à saúde sexual e reprodutiva tem sido considerada uma das áreas de atuação prioritárias da Atenção Básica pelo Ministério da Saúde e tem por princípio a abordagem integral e a promoção dos direitos humanos, ${ }^{1}$ entre os quais se incluem os direitos sexuais e os reprodutivos. De acordo com as orientações desse ministério, não é tarefa simples, considerando a complexidade na abordagem dos temas pertinentes aos determinantes socioculturais que envolvem as situações de saúde, o que exige maior preparação dos profissionais, incluindo o desenvolvimento de metodologias adequadas. 
Os profissionais, seja nos sistemas de saúde ou da educação, sentem-se despreparados para abordar os aspectos relacionados à saúde sexual e reprodutiva, dentre estes o combate à homofobia, a prevenção de gravidez e das DST/Aids, por se tratarem de questões polêmicas envolvendo preconceitos e tabus. Interessa destacar que ainda existem ações de saúde e de educação que visam assegurar o alcance dos objetivos das políticas nesses campos, voltadas para a diminuição das desigualdades sociais, no que tange às demarcações de gênero e de orientação sexual. No entanto, muitas delas assumem caráter prescritivo, estando alheias aos significados das experiências de vida dos jovens e resultando em reduzido alcance das ações nesse campo.

Observa-se, em meio às normatizações da saúde e da educação, que pretendem informar qual a melhor conduta em relação aos cuidados com o corpo - incluindo práticas alimentares, uso de drogas, prevenção de doenças e evitação da gravidez - reduzido impacto dessas ações. Há de se atentar, neste sentido, para a existência de construções sociais do corpo que norteiam as condutas no universo da cultura juvenil que não podem ser ignoradas.

Como iremos apresentar posteriormente, identificamos, nos discursos sociais adotados pelas revistas e articulados pelos jovens, que os ideais de corpo associados à magreza e à beleza se coadunam aos dispositivos sociais de controle da sexualidade. O objetivo de alcançar tais ideais por parte dos jovens, sobretudo as jovens, mas também as adultas, resulta na constituição de um grupo que se torna uma das maiores vítimas dos distúrbios alimentares.

Segundo Ferreira, ${ }^{2}$ a obesidade, a bulimia e a anorexia nervosa sintetizam o aprendizado dos mecanismos de controle social e estigmatização corporal como discutido na literatura. Nesta direção, o tema da alimentação e do controle das práticas alimentares, quando analisado sob o prisma de uma perspectiva cultural e social, encontra-se intimamente implicado na análise do corpo jovem. Este trabalho visa, juntamente com os já existentes, contribuir para a melhor compreensão do tema entre jovens.

As questões de saúde sexual e reprodutiva, ainda que de modo diferenciado, são também contempladas em jornais e revistas de circulação nacional. Para Rios, ${ }^{3}$ a organização social e a visibilidade das questões envolvendo a saúde sexual e reprodutiva na mídia ganham contornos específicos a depender dos temas tratados e do direcionamento dos meios de comunicação aos diferentes públicos. De acordo com as informações do Ministério da Saúde, ${ }^{1}$ as DSTs têm sido muito discutidas em fóruns científicos, assim como nos meios de comunicação de massa, particularmente por sua associação ao maior risco de infecção pelo vírus da imunodeficiência humana (HIV) por transmissão sexual entre homens, mulheres adultos e jovens.

Supõe-se, portanto, haver uma circulação das diferentes temáticas alcançando grande parte do público jovem leitor, internauta ou telespectador, ajudando a informar atitudes nos diferentes grupos da sociedade. As revistas femininas juvenis incorporam-se a esse cenário como mais um 
ator que vem engendrar a produção social dos sentidos atribuídos à construção do corpo e da sexualidade na fase de iniciação sexual entre os jovens.

Mediante este cenário cabe-nos questionar: como os jovens, imersos em um contexto social de intensa circulação e acesso a informações, têm construído uma percepção crítica no que se refere à experiência da sexualidade a partir dos marcos dos direitos sexuais que preconizam a autonomia e liberdade de escolha? Como os meios de comunicação refletem a realidade e as práticas sexuais dos jovens?

Com o enfoque na iniciação sexual e seus modos de representações entre a mídia e os jovens, este estudo apresenta os resultados obtidos através de pesquisa realizada com jovens escolares de classes populares, em uma escola pública estadual localizada no município de Queimados, Baixada Fluminense, estado do Rio de Janeiro, onde residem. O objetivo foi conhecer as percepções construídas acerca do corpo, da sexualidade e das relações de gênero na interface com os discursos sociais, por meio das revistas femininas juvenis Capricho e Atrevida, duas modalidades de publicações comerciais.

O intuito das revistas femininas juvenis, incluindo Capricho, Atrevida e suas congêneres, não é construir uma estrutura pedagógica direta, tal como podemos observar no jornalismo e na divulgação científica, a exemplo de Scientific American, Ciência Hoje e ComCiência na cobertura de temas de saúde. Todavia, observamos que os discursos que circulam nessas revistas repercutem entre os jovens, produzindo sentidos e refletindo os valores presentes na sociedade no que concerne às relações de gênero e à orientação sexual. Portanto, quando falamos de informação sobre sexualidade, no que se refere às revistas femininas juvenis, não afirmamos haver um compromisso deste meio com os conteúdos científicos propriamente ditos, mas uma produção de textos e imagens direcionados ao público jovem que exprimem valores sociais e morais em torno da experiência sexual.

Segundo Fischer, estes são "saberes que de alguma forma se dirigem à "educação" das pessoas, ensinando-lhes modos de ser e estar na cultura em que vivem (p.153). Assim, trabalhamos com a premissa de que os meios de comunicação produzem conhecimento, ainda que não especializado, nesse campo, entre os jovens. ${ }^{a}$

a Entre as jovens do Rio de Janeiro, quando perguntadas sobre onde obtiveram as primeiras informações sobre DST/Aids, observa-se um empate entre os serviços de saúde e as revistas femininas, com $12 \%$ cada uma. Com relação à escola, $28 \%$ dessas mulheres jovens do Rio de Janeiro informaram ser esta a responsável pela disseminação de informações sobre relação sexual; 34\% sobre gravidez/contracepção e 56\% sobre DST/Aids (Bozon \& Heilborn, p.160, 2006). Enquanto a escola representa para 50\% dos homens entrevistados no Rio de Janeiro um espaço para obtenção de informação sobre DST/Aids. Entre as mulheres que participaram da entrevista na mesma cidade, este índice chega a 56\%, para aquisição de informações e prevenção às DST/Aids (ibid., p.160, 2006). 
São apresentados aqui os principais elementos que caracterizam as revistas femininas juvenis Capricho e Atrevida, contextualizando-as no cenário da iniciação sexual como parte da experiência da sexualidade juvenil. Este aprendizado se caracterizou por questões levantadas sobre as relações de gênero, intrínsecas às práticas sexuais, de prevenção e reprodução. Nesta direção, a ótica dos jovens escolares esteve mediada pela produção das revistas analisadas, refletindo uma negociação de sentidos permanente com as revistas femininas juvenis cuja análise se norteia pela perspectiva sócio-antropológica conjugada aos referenciais da Comunicação Social.

\section{Iniciação sexual nas páginas das revistas femininas juvenis:} referenciais e contexto da investigação

A construção de uma metodologia de trabalho com as revistas Capricho e Atrevida, direcionada ao contexto escolar, caracterizou-se pela conjugação de diferentes perspectivas teóricas. A aproximação entre diferentes perspectivas, tais como a sócio-antropológica, referenciadas neste estudo por Minayo, ${ }^{5}$ Foote-Whyte ${ }^{6}$ e Víctora et al., ${ }^{7}$ conjugou-se à dos Estudos de Recepção, segundo Martín-Barbero, ${ }^{8}$ Sousa ${ }^{9}$ e Leal. ${ }^{10}$ Isto proporcionou uma leitura crítica dos meios de comunicação construída na interação com os jovens no contexto da pesquisa.

O estudo de cunho etnográfico teve por objetivo, portanto, acompanhar o processo de interação com as revistas Capricho e Atrevida, os modos de ressignificação e as percepções entre os jovens escolares envolvendo a entrada na sexualidade com um parceiro. A análise da leitura das revistas Capricho e Atrevida pelos jovens, concebidas como mediações culturais. Mediações tendo por pressupostos o conceito de cultura introduzido por Geertz ${ }^{11}$ e Da Matta, ${ }^{12}$ como um sistema de significados que permite entender os comportamentos em sua ação simbólica; reflexões sobre a cultura a partir de suas mediações representam a sistematização de valores e ideologias nas realidades sociais. A recepção, como um conceito no âmbito da Comunicação Social, é um lugar de onde são negociadas e construídas as práticas discursivas, e onde também se expressam as relações de poder. De acordo com Martín-Barbero,, "o campo daquilo que denominamos mediações é constituído pelos dispositivos através dos quais a hegemonia transforma por dentro o sentido do trabalho e da vida da comunidade"(p.274). O conceito-chave de mediação é explorado para a produção de uma leitura crítica dos meios em consonância com a perspectiva sócio-antropológica, que, segundo Minayo, ${ }^{5}$ é aquela que privilegia as percepções, relações e representações dos grupos de escolares, tendo em vista as mediações culturais.

Estudos em Comunicação Social informam que as revistas publicadas no Brasil obedecem à lógica de segmentação do mercado editorial, sendo produzidas a partir da delimitação de assuntos de interesse do público consumidor, incluindo-se as revistas femininas juvenis. Para Mira, ${ }^{13} \mathrm{o}$ formato editorial da revista Capricho (e suas congêneres) alia a ênfase aos artigos de moda, sexo e 
relacionamentos. A discursividade entre as revistas femininas juvenis e as publicações femininas como Claudia, Marie Claire ou Ana Maria parece desempenhar a função de manutenção e formação de público leitor e consumidor desse gênero. De acordo com Freire Filho, ${ }^{14}$ nesses periódicos, consumo e identidade se tornaram partes indissociáveis do estilo de vida preconizado pelas publicações que traduzem a autenticidade feminina como "personalidade forte". Tais distinções entre masculino e feminino integram a rede comunicativa dos jovens, contribuindo para a construção da identidade social juvenil.

De modo convergente, dados da literatura, a partir da perspectiva antropológica, apontam que as imagens do corpo produzidas socialmente apresentam marcas distintivas de gênero expressas a partir da diferença biológica. No entanto, segundo Heilborn, ${ }^{15}$ a sexualidade, nesta perspectiva, é compreendida como "um produto de diferentes cenários, e não apenas como derivada do funcionamento biopsíquico dos sujeitos".(p.35)

As revistas femininas juvenis correspondem a uma mediação cultural cujos discursos circulantes oferecem à análise um conjunto de significados atribuídos ao corpo e à sexualidade. O estudo realizado com as revistas Capricho e Atrevida focalizou as concepções acerca de corpo, gênero, sexualidade e orientação sexual, valendo-se de diferentes recursos e estratégias metodológicas aqui resumidas": 1) Caracterização e análise das revistas Capricho e Atrevidac; 2) Atividade do "Saco sem-vergonha" e "O que é sexualidade?", desenvolvida com os jovens, em que perguntas e respostas foram analisadas; 3) "Produção de Cartazes" a partir das matérias produzidas nas revistas; e 4) Grupos de Discussão com os jovens, sobre experiência da sexualidade e produção das revistas. Compõem o cenário do trabalho de campo o ambiente escolar, uma interação e aproximação da pesquisadora com os jovens, e destes com as revistas femininas juvenis, sobretudo as inquietações e dúvidas dirigidas ao pesquisador pelos próprios alunos durante as atividades realizadas.

Os jovens que participaram voluntariamente do estudo tinham idades entre 12 e 16 anos, eram oriundos das camadas populares, com pouco ou nenhum acesso a bens culturais no município de Queimados, no Rio de Janeiro. ${ }^{4}$ Os alunos pertenciam a duas turmas de $8^{\underline{o}}$ ano do Ensino.

Esta pesquisa foi aprovada pelo Comitê de Ética em Pesquisa CEP/ Fiocruz após apreciação do colegiado por atender as exigências às diretrizes da Resolução 196/96 do Conselho Nacional de Saúde (CONEP), Sob o protocolo de número 600/2011.

b Uma descrição detalhada do percurso metodológico pode ser encontrada no estudo intitulado "Corpo, sexualidade, gênero e as mediações culturais em revistas femininas juvenis: possibilidades de uso para o ensino não-formal”, sob a orientação da Dra Eliane Portes Vargas, desenvolvida no Programa de Pós-graduação em Ensino em Biociências e Saúde. Apoio Capes.

c Este resultado encontra-se descrito no artigo Revistas Femininas Juvenis e a Educação Sexual no Ensino de Ciências - Práxis. 
Fundamental e as diferenças na experiência sexual representou um fator de distinção relevante entre os dois grupos: (1) "sexualmente menos iniciados", os alunos de menor faixa etária, pertencentes à turma de "não repetentes" e que indicavam traços de menor iniciação sexual; (2) "sexualmente mais iniciados", aqueles cuja faixa etária não correspondia mais à série escolar, cujos traços indicavam maior iniciação sexual, em sua maioria. Dessa forma, a adoção dos termos "mais iniciados" e "menos iniciados" surge a partir de uma percepção do envolvimento dos alunos com suas vivências sexo-afetivas, e não necessariamente, de suas práticas sexuais.

\section{Imagens do corpo, sexualidade e gênero na ótica dos escolares}

A análise das revistas indicou haver a disseminação de um padrão de beleza que, em maior ou menor intensidade, contribui para a formação de um senso estético de feminilidade e masculinidade. A leitura que os mais iniciados fizeram das revistas exprimiu uma imagem compartilhada de si, sendo a pouca opção de corpos masculinos uma das ausências notadas pelos meninos: "Eu escolhi esse daí porque nas revistas tinham muito poucos homens, e sim mais mulheres", opinou Eduardo, aluno mais iniciado, de 16 anos. Entre os meninos menos iniciados, uma reduzida identificação com a autoimagem nas revistas predominou, pela condição social dos ídolos, bem distante de sua experiência: "Nessas revistas só tem playboy, as meninas ficam apaixonadas, mas eles nem parecem pessoas de verdade", opinou Guilherme, aluno menos iniciado, de 14 anos. A fala de Guilherme exprime um sentimento de exclusão recorrente entre os meninos mediante os padrões de masculinidade e consumo veiculados nas revistas.

A identificação das meninas mais iniciadas esteve mais relacionada à personalidade, ou de predicados atribuídos ao sexo feminino. Para Maria Eduarda, 15 anos, a expressão de si conjuga feminilidade à afetividade, corroborando o argumento que, segundo Heilborn et al.," "na construção social do gênero feminino há subsunção do sexo à afetividade, aqui designada como perspectiva relacional referente à sexualidade”. A associação de feminilidade à afetividade também surgiu na discussão entre meninos e meninas sobre a correspondência entre "ser a mulher" e "sexo frágil". No processo de discussão, confirmaram a naturalização da fragilidade feminina "porque elas se apaixonam mais rápido". Segundo os meninos e meninas mais iniciados, protagonistas nessa discussão, o não enquadramento das meninas nessa prescrição de gênero resulta na sua identificação como meninas "fáceis".

Os conflitos com a autoimagem corporal, retratados através das imagens das revistas, apareceram entre as meninas mais iniciadas, ao admitirem sentir constrangimentos quanto ao formato dos seus corpos e como estes interferem na iniciação sexual. Monique, 15 anos, e Sabrina, 16, ambas alunas do grupo das "mais iniciadas", pontuam, respectivamente, as impressões com a autoimagem corporal: 
A minha maior preocupação com a primeira vez, são três coisas: medo de engravidar, doenças, e a vergonha que eu tenho de mim, do meu corpo. Isso é o que mais me incomoda, mais do que os outros medos. Rola a insegurança, querendo ou não rola a insegurança, porque eu fico pensando muito no que ele vai pensar depois. Por eu ter vergonha eu não sei o que ele vai falar e pensar depois, é isso. Só se eu estiver muito segura daquilo que eu quero, mas sei lá.

Eu tive a minha primeira relação sexual com meu primeiro namorado, nós ficamos juntos por dois anos. Eu tenho muita vergonha do meu corpo, e por isso demorou uns dois anos pra gente fazer alguma coisa.

Nota-se a aptidão das revistas em captar os sentimentos de inadequação e constrangimentos corporais, em especial nas meninas nesse período de transformação e desenvolvimento biopsíquico. A relação que as meninas demonstraram estabelecer com o próprio corpo e seus reflexos na autoestima e no desempenho sexual também foi relatada na revista Capricho, ${ }^{17}$ como a seguir:

Só me sinto preparada para transar se estou de bem com o meu corpo. Além disso, é sempre bom ter uma camisinha na bolsa. Vai que ele esquece! Dá um pouco de vergonha ficar sem roupa na frente dele. Por isso, a maioria prefere diminuir a luz do quarto!

Os constrangimentos corporais surgem tanto nas revistas quanto nos discursos dos jovens, construindo suas identidades sociais e sexuais, vinculadas à imagem corporal - ou seja, o referencial de um corpo belo e socialmente aceito que, neste caso, circula nos dispositivos discursivos das revistas Capricho e Atrevida. Embora este estudo não tenha tido como objeto a construção da imagem corporal para a expressão das práticas sexuais, a identificação dos discursos sociais adotados nas revistas articulados também pelos jovens delimita a expressão da sexualidade, ao revelar os ideais de magreza e beleza como dispositivos sociais de controle da sexualidade.

Para Ferreira, ${ }^{2}$ mulheres (de todas as idades) figuram como as maiores vítimas dos distúrbios alimentares, na qual a obesidade, a bulimia e anorexia nervosa sintetizam o aprendizado dos mecanismos de controle social e estigmatização corporal. Dessa forma, o corpo também aparece como a principal referência para a escolha do parceiro, sendo a principal justificativa dos jovens do sexo masculino no momento da conquista amorosa. Entre os meninos menos iniciados e os mais iniciados, a beleza física, a aparência do corpo, ser um corpo atraente, são fatores determinantes na escolha do parceiro. A aparência feminina é a qualidade mais valorizada entre eles. Os atributos físicos vêm acompanhados de outros elementos nessa escolha, relacionando-se aos valores familiares, experiência e idade da parceira. Segundo o depoimento de Fernando, 12 anos, aluno menos iniciado: 
Eu não tenho namorada. Mas primeiramente, uma garota bonita, que goste de mim e eu goste dela. O meu pai falou uma coisa comigo: "Se você pegar uma garota mais nova que você, aí vai desenvolvendo ela do seu jeito, e depois ela não vai fugir. Uma pessoa mais nova você vai desenvolvendo do seu jeito, e depois que ela fica com a mente formada, ai é um pouco mais fácil”. Isto é tipo uma opinião para namorar, né?

Para as meninas, tanto as mais iniciadas quanto as menos iniciadas, prevalecem sobre o corpo e a beleza física algumas características de personalidade no momento da conquista amorosa. Os meninos precisam saber conversar e ser mais experientes. Isso os torna mais atraentes para as meninas menos experientes sexual e afetivamente, integrando-se às idealizações e preferências de parceiro. E ainda segundo a aluna menos iniciada Nicole, 14 anos:

Eu acho que é a imagem corporal que determina na conquista. Mas a imagem não é tudo. Pode ser um garoto bonito, mas se ele não souber conversar, eu não vou ficar com ele. Se ele abrir a boca e falar besteira aí não dá.

As meninas declararam ser determinante na decisão de terem a primeira relação sexual se sentirem seguras com o parceiro; ser um parceiro para a vida toda ou um namorado, não foi considerado tão importante assim. No resultado da enquete realizada pela Capricho, ${ }^{17}$ as opiniões das meninas se aproximaram da percepção das jovens da pesquisa, onde " $50,5 \%$ das meninas transariam com um garoto sem compromisso, desde que eles se gostassem”, ao opinarem sobre transar sem compromisso.

As relações de consumo também demonstram influenciar na preferência e escolha do parceiro. As diferenças entre meninos e meninas aparecem na preferência delas por meninos famosos, pois para estas a fama pressupõe riqueza. Contudo, demonstram ter criticidade quanto às funções dos ídolos no imaginário feminino, um ideal de parceiro bonito e rico. Reconhecem que os meninos famosos são inatingíveis, como na seguinte afirmação de Luiza, 14 anos: "Um menino famoso serve pra gente sonhar vários sonhos bons. A gente sabe que não vai arrumar um desses, mas a gente admira...". Os meninos menos iniciados e mais iniciados não consideram importante que as mulheres sejam ricas e famosas, mas que tenham um corpo bonito, peito e bunda. Corpo e beleza figuram como os atributos principais.

As percepções masculina e feminina na preferência de parceiro e consumo se complementam. A ênfase feminina do interesse dos meninos em sexo, e a masculina no interesse das meninas no dinheiro deles trouxeram à tona aspectos das relações entre os gêneros que os meios engendram na apresentação das imagens dos relacionamentos afetivo-sexuais dos jovens. Por outro lado, os jovens expressam uma visão crítica sobre os discursos sociais que circulam nas revistas, conforme expressado por Fabiano, aluno menos iniciado (13 anos): 
Essas revistas falam mais de homens famosos, né? Eu acho que essas revistas femininas não são boas, porque o certo é elas falarem de todo tipo de menino. Menino que tem dinheiro, menino feio, bonito. Falar de todos os modos de meninos que existem, mas elas não falam, só falam de meninos ricos e bonitos.

Para Freire Filho, ${ }^{14}$ a cultura do consumo perpassa as identidades contemporâneas "em que os atos de compra ou consumo expressam gosto, valores, visão de mundo, inserção social...”. A retórica amigável trazida por Capricho e Atrevida envolve as leitoras, mas demonstrou ter efeito opressivo para os meninos que expressaram um sentimento de marginalização e exclusão por não estarem à altura dos astros ricos e famosos em circulação nas revistas. Observa-se que a compensação feminina para a pouca importância dada à beleza masculina se estrutura através do desejo que o homem tenha dinheiro para conquistá-las, o que se traduz na expectativa social do desempenho do homem na sociedade. Assim, de acordo com Louro, ${ }^{18}$ supõe-se que o simbolismo do poder de consumo estaria produzindo reverberações na sexualidade desses jovens com efeitos diretos em seus corpos.

O fato de "meninos experientes" serem tão valorizados quanto as meninas virgens, ou menos experientes, aproxima os ideais de parceiro deste grupo, formando o primeiro traço de coesão que os identifica como menos iniciados. As expectativas de ambos caracterizam a complementaridade na busca pelo parceiro. Em outras palavras, os meninos querem se relacionar com meninas menos experientes (ou virgens), e as meninas preferem se aproximar dos meninos mais experientes. Tais preferências tendem a inviabilizar que desenvolvam suas primeiras experiências sexuais entre si. O intercâmbio de experiências na preferência por parceiros mais iniciados e menos iniciados sexualmente caracterizaria a transição nos traços de intensidade das experiências sexuais.

\section{Iniciação sexual}

As práticas de iniciação dos jovens culminam na decisão de ter a primeira relação sexual. Na percepção desses jovens, tal decisão é tomada majoritariamente pela mulher, sendo pouco conversada entre o casal; recai também sobre ela a responsabilidade pela prevenção às DSTs e, principalmente, a gravidez. A decisão de ter a primeira relação sexual configura-se como parte do jogo amoroso em que o papel da menina é negar, valorizando-se por ser virgem, cabendo a ela decidir em que momento ceder. E aos meninos é reservado o papel de pressionar para obter o que, como eles mesmos reconhecem mais desejar: uma relação sexual. Conforme encontrado em Heilborn et al., "[r]esistência da mulher e insistência do homem fazem parte do regime ideal das relações de gênero. A mulher deve saber julgar em que momentos pode conceder maior intimidade corporal".(p.211) 
Sobre a pressão que sofrem para transar, identificada como parte das práticas de iniciação, os meninos e meninas menos iniciados demonstraram identificação com o discurso das revistas, ao encontrarem uma resposta correspondente à seguinte dúvida na revista Capricho:17 "Vocês fariam sexo com uma pessoa só para deixá-la feliz?”. Os alunos e alunas puderam expressar suas opiniões sobre o assunto: "62\% das garotas já foram pressionadas por um garoto para fazer sexo". E ainda: "60\% das leitoras não fariam a vontade do garoto nem se gostassem muito dele. Sexo é algo muito importante!”. A revista Atrevida abordou o assunto com o seguinte depoimento, na edição de março de 2011:19

Namoro um garoto mais velho. Ele não é mais virgem, mas eu sou. Por isso, estamos vivendo uma fase de terror em nosso relacionamento, pois ele quer ter relações sexuais e eu ainda não me considero pronta. Já conversamos sobre o assunto e ele disse que é complicado esperar tanto. Nosso namoro está limitado, pois quando ele não aguentar mais, a única saída será terminar tudo. E não queremos que isso aconteça, pois gostamos muito um do outro. O que eu faço?

O grupo dos alunos e alunas menos iniciados também demonstrou valorizar a opinião de um especialista, para confirmarem suas convicções, como se também estivessem mandando um recado para os demais colegas, ao reproduzirem em seus trabalhos o trecho recortado da revista Capricho, com a opinião do médico Calvino Fernandes: ${ }^{17}$

Se você está sendo pressionada, não ceda só porque ele quer. Senão você pode se arrepender depois! Converse com o menino e reforce o quanto gosta dele, mas explique que não quer transar ainda. Se ele se importar com você de verdade, vai entender. Agora, se ele ficar bravo, caia fora: um menino que pensa só na própria satisfação não vale a pena!

Depreende-se que, independentemente de serem mais ou menos iniciados sexualmente, meninos e meninas reconhecem como legítima a pressão que as meninas sofrem para transar. Segundo Luiza, aluna menos iniciada de 13 anos: "As meninas sofrem pressão pra transar porque eu acho que os meninos pedem uma prova de amor. E as meninas ainda sofrem muito essa pressão". Com menor expressividade, as meninas mais iniciadas também reconheceram haver uma pressão feminina sobre elas mesmas para terem a primeira relação sexual. Para Tatiane, aluna mais iniciada, de 15 anos: "Eu acho que o menino faz pressão, mas têm amigas que mesmo que a gente não se sinta pronta ficam incentivando".

Assim como abordado pelas revistas, implicitamente, a pressão masculina se organiza de modo a parecer que esta é uma decisão unicamente feminina. A decisão de transar aparece, em alguns momentos, influenciada pela vontade masculina, que pressiona com o consequente término do relacionamento, caso elas não cedam. Tal como aparece representada na fala de Renata, aluna 
mais iniciada, de 15 anos, a opinião desses jovens: "Quem é mais ansioso é o menino, mas é a menina que decide, porque ele não vai pegar ela à força, mas o menino pressiona”. Ou ainda, segundo o aluno mais iniciado José, de 13 anos, através da opinião com justificativa nas mudanças fisiológicas ocorridas no corpo masculino: "Os homens fazem pressão por causa dos hormônios. Os hormônios é que fazem a pressão”.

A virgindade aparece como sendo mais valorizada entre os meninos e meninas menos iniciados. Reconhece-se a ênfase dada à experiência sexual masculina, sendo a virgindade feminina sua equivalente dentre os valores culturais para a entrada na sexualidade, de acordo com Sofia, menos iniciada, 15 anos: "É que para os homens não tem esse negócio de primeira vez. Para eles quanto mais vezes for, melhor". Quanto menos experiente a menina for, isso seria considerada uma vantagem para os meninos. Estes foram unânimes ao rejeitarem a possibilidade de se casarem com uma menina que não seja mais virgem. Enquanto as meninas se mostraram mais contundentes em suas opiniões, conforme opinou a aluna menos iniciada Patrícia, de 13 anos: "Eu acho que a virgindade sempre foi importante. Imagina uma menina da igreja que sempre foi toda certinha casar sem estar virgem?".

Entre o grupo dos mais iniciados, a virgindade já se apresenta um pouco diferenciada em relação ao outro grupo, com significados diferentes, dando novos contornos à discussão. Os alunos reconhecem sua importância e seu valor cultural, mas acreditam que os jovens de sua idade não mais acalentam a expectativa de se casarem virgens ou de que o primeiro parceiro seja o único, acompanhando-o por toda a vida. Conforme elucidado no depoimento da aluna mais iniciada, Tatiane, de 15 anos:

Eu acho que tanto para namorar ou para ter a primeira vez você tem que ter certeza que é aquilo mesmo que quer que vai valer a pena. Por mais que eu não fique com a pessoa pra sempre, mas que eu tenha a lembrança que foi uma pessoa especial, num lugar especial. Mas às vezes não é nada daquilo que a gente pensa. Se você se sente preparada, pronta, e acha que vai ser especial pra você, eu acho que não tem problema nenhum.

A expectativa dos meninos e meninas mais iniciados é de que o momento da primeira relação sexual seja especial, significando um rito de passagem; importante para ser lembrado por toda a vida, e não necessariamente acompanhado de uma experiência afetiva, como uma experiência amorosa relevante. O que está sendo considerado mais importante, em especial para as meninas mais iniciadas, é a segurança com relação ao próprio corpo, mesmo que esta não represente para elas a negociação para a prática de sexo seguro. O desejo por segurança se traduz na confiança pelos sentimentos do parceiro.

Embora tenham demonstrado expectativas distintas quanto à virgindade feminina e masculina, em comum os dois grupos aqui analisados reconhecem que esse regime ideal nas relações de 
gênero é o que vem servindo de parâmetro para a construção de suas percepções. De acordo com Bozon \& Heilborn, ${ }^{20}$ a pressão que as meninas sabem sofrer é um sentimento comum a muitas mulheres; a resistência à penetração vaginal parece subsistir nas relações como "ponto central da negociação entre os casais", e revela se sustentar através dos discursos de autoconfiança, a relação com o corpo e o próprio prazer feminino, influenciando na decisão.

\section{Práticas sexuais e práticas preventivas}

As adoções de práticas preventivas para a iniciação sexual apareceram entre os jovens subjacentes ao medo da gravidez. Esta foi a maior preocupação demonstrada pelas meninas envolvidas no estudo, fossem elas mais ou menos iniciadas. Para Renata, aluna menos iniciada, de 15 anos: "Pegar doença não me preocupa, mas pegar uma gravidez assim...".

A atitude masculina mediante a gravidez se apresentou difusa, ou seja, aqueles que estiveram ou estão namorando demonstraram maior preocupação com a possibilidade de engravidar a parceira, conforme demonstrou Arthur, aluno mais iniciado, de 17 anos: "Eu me preocupo com tudo, com doença, com gravidez. Pergunto, se ela está bem, se a menstruação 'desceu'”. Já aqueles que não declararam ter parceiras fixas consideraram que esta deve ser uma preocupação feminina, conforme demonstrado no depoimento de Peterson, aluno mais iniciado, de 17 anos: "Cara, eu acho que o homem não pensa nisso, não. Mas acho que a mulher deve pensar. Na hora que ele vai pegar a garota ninguém pensa se ela vai engravidar". As opiniões emitidas pelos jovens menos e mais iniciados sobre o uso do preservativo se assemelham aos resultados de enquete realizada pela revista Capricho, segundo os quais "engravidar é o maior medo que rola depois do sexo para a maioria das garotas". ${ }^{17}$

O uso da camisinha também apareceu permeado de mitos e resistências. Os alunos mais iniciados suscitaram a possibilidade de a camisinha furar e não proteger contra a gravidez, podendo conter furos por onde passaria o esperma. Esta visão sugere que, segundo esses jovens, o uso do preservativo se tornaria dispensável, antevendo as possibilidades de falha na prevenção à gravidez.

Sobre a possibilidade do uso de outros métodos contraceptivos, as meninas mais iniciadas reconheceram que muitas delas ainda têm medo de usar a pílula anticoncepcional, que poderia até causar infertilidade. As justificativas delineadas pelos mais e menos iniciados sobre o uso da camisinha sugerem uma resistência masculina de adesão ao preservativo, com a principal alegação de que, quando a menina é virgem, seu uso se tornaria dispensável, conforme opinou Nicole, aluna mais iniciada, de 14 anos: "Os meninos dizem que incomoda, e não precisa. Mas mesmo que os dois sejam virgens eu acho que têm que usar camisinha”. Nota-se que a responsabilidade pelo uso da camisinha é pouco conversada entre os parceiros, e as meninas denunciam os preconceitos 
que enfrentariam caso decidissem carregar a camisinha em suas bolsas. Logo, por razões que convergem, mais iniciados e menos iniciados concordam que quem deve carregar a camisinha é o homem. Tal crença aparece no discurso de Maria Eduarda, aluna mais iniciada, de 15 anos:

Quem leva a camisinha para o primeiro encontro é o homem. Se a mulher levar, ela é piranha. Uma mulher também pode levar, mas o certo é o homem levar. Mas se ela levar ela também vai estar se prevenindo. Mas se a gente levar o menino te chama de piranha, e aí?

Há, no entanto, uma complexidade na questão envolvendo as relações de gênero, que se situa entre a responsabilidade de ter a camisinha, atribuída ao homem, e a decisão de usá-la efetivamente, reconhecida como sendo das mulheres. Em consonância com o já registrado por Britzman ${ }^{21} \mathrm{e}$ Souza, ${ }^{22}$ observa-se que assim como alunos e alunas, em sua maioria, atenderam às expectativas sociais construídas para cada gênero, as formulações acerca do uso da camisinha fazem parte da cultura escolar permeada pelo discurso da prevenção prevalente no campo da sexualidade (ou da saúde), sendo imperativo seu uso, sem levar em consideração a compreensão de questões que fazem parte da intimidade dos jovens.

\section{Reprodução}

A reprodução humana constituiu outro aspecto de interesse dos alunos explorado a partir do funcionamento biológico do corpo. Segundo Leal, ${ }^{10}$ o período fértil e a gravidez aparecem vinculados ao sangue menstrual. A partir dessas associações feitas pelos alunos, foi possível captar em quais aspectos há correspondência das revistas com as demandas dos alunos mais e dos menos iniciados.

As formas de negociação e representação produzidas mediante os conteúdos ofertados por Capricho e Atrevida puderam ser compreendidas a partir das seguintes dúvidas sobre o tema: "Pode transar menstruada?". Isso demonstra que os alunos mais e os menos iniciados fazem as conexões do período fértil ao período menstrual, aumentando assim o risco de gravidez nesta fase. Veremos que, para construírem suas respostas, recorreram às informações contidas nas revistas analisadas, bem como aos seus universos conceituais, expressando seus conhecimentos sobre o funcionamento do corpo. Conforme publicado na revista Atrevida na edição de junho de 2011:23

Percebi que quando estou menstruada é mais fácil chegar ao orgasmo na masturbação. Será que o grau de excitação é realmente maior durante a menstruação ou estou com uma impressão errada sobre esse tema? Pode ter sido só uma coincidência? Vocês podem me dizer se é verdade que as meninas ficam mais sensíveis nessa fase? Resposta: Sim, é verdade que nessa fase, muitas mulheres relatam aumento de desejo sexual 
e excitação. Esse fato tem explicação na biologia. Isto se deve à produção de estrogênio e de testosterona, hormônios que influenciam muito a sexualidade feminina. Aproveite esse período! Não há contraindicação para a masturbação e para o sexo (com proteção) durante a menstruação.

Embora a revista não tenha mencionado haver maior risco de gravidez durante o período menstrual, também não esclareceu aos leitores em que momento do ciclo a mesma poderia ocorrer. Contudo, a resposta formulada por outro grupo de alunos menos iniciados sugere que a questão de fundo levantada pela turma se refira à possibilidade da menina engravidar se mantiver relações sexuais durante a menstruação. Na análise do conjunto de respostas construídas pelos alunos(as) menos iniciados, é possível captar a inquietação sobre o processo reprodutivo com a leitura das demais respostas complementares.

Ao retomarmos a pergunta sobre se pode transar menstruada: "Pode. Só que não é recomendado porque durante a menstruação corre mais riscos de a mulher engravidar”, de acordo com os alunos(as) menos iniciados, esta preocupação fica mais perceptível. E ainda, complementarmente, na revista Atrevida podemos perceber, no recorte desta única frase, haver mais que uma dúvida relacionando a concepção do corpo feminino ao seu período fértil: "Eu gostaria de saber se é possível uma menina engravidar se fizer sexo enquanto estiver menstruada”. Representações semelhantes já foram registradas por Leal, ${ }^{10}$ que em pesquisa com grupos de mulheres e homens de camadas populares constatou que o período fértil coincide com o período menstrual, o mais propício à concepção, sendo seu equivalente masculino o esperma.

A relação sexual é representada como um momento onde a troca de fluidos corporais ocorrem, trata-se essencialmente de uma relação social onde se dá uma troca, fluidos corporais são substâncias transmissoras tanto daquilo que poder ser poluido, quanto de vida, emoções, substâncias morais.

Os fluidos corporais continuaram a ser explorados pelos alunos que puderam sistematizar suas crenças apoiando-se nas revistas para reafirmarem ou reconstruírem suas concepções sobre práticas sexuais e reprodução. A partir da dúvida: "Por que sai a goza?”, é perceptível que nas elaborações feitas pelos menos iniciados, há mais uma vez a associação do esperma à menstruação, englobando a ovulação e o período fértil. Conforme demonstrado por eles na elaboração textual dos alunos conjugada à resposta encontrada na revista Atrevida: "Quando a sai é porque a pessoa está excitada, isso é como se fosse um corrimento que sai dos homens como sai das mulheres”. E ainda, como registrado pela revista Atrevida, em texto publicado em março de 2011:19

Eu fiquei menstruada não faz muito tempo, mas já sinto algo diferente quando se trata de sexo. Geralmente, na minha calcinha, sai um liquido branco, uma gosma. Minhas amigas dizem que é gozo. Isso é verdade? 
Resposta: $O$ fato de já ter menstruado indica que você está ovulando e produzindo estrogênio - hormônio sexual responsável por todas as mudanças do corpo e da menina. Você também vai sentir uma secreção na vagina por conta da ação deste hormônio, que varia conforme o seu ciclo menstrual. É normal você começar a sentir desejo sexual e se excitar. Quando isso acontece, sua vagina fica úmida, mas isso não é gozar, é a sua lubrificação. Na maioria das vezes, a mulher não elimina nenhum líquido quando alcança o orgasmo.

O entendimento sobre reprodução que os alunos demonstraram ter indica que seus conhecimentos empíricos se sobrepõem ao conhecimento de bases científicas sobre o funcionamento do corpo. Embora compreendam a menarca como a fase que simboliza a transição de menina a mulher, iniciando o ciclo reprodutivo, os menos iniciados não distinguem as fases do ciclo menstrual - ou seja, que a mulher não ovula todos os dias do mês. Assim, associadas ao período menstrual, obtivemos as seguintes construções dos alunos em diálogo com as revistas. "Quando as mulheres começam a produzir os óvulos?”: "Quando a mulher tem a sua primeira menstruação, a menarca, por volta dos 12 a 13 anos”, produção textual dos alunos(as) menos iniciados. Essa elaboração textual se justapõe ao discurso mais técnico-científico da revista Atrevida: "O fato de já ter menstruado indica que você está ovulando e produzindo estrogênio - hormônio responsável por todas as mudanças do corpo da menina". ${ }^{19}$

Os menos iniciados recorreram a uma metáfora médica, a injeção, para melhor representar o momento da fecundação ou o ato sexual: "Quando injetamos o espermatozoide na mulher ela corre o risco de engravidar?” De acordo com Martin, ${ }^{24}$ esta é uma das manifestações de existência da cultura médica perpassando a cultura popular. "Com certeza, é um fato que acontece muito e muitas meninas e mulheres engravidam por isso", dos alunos(as) menos iniciados. Como a resposta não informa que somente ocorrerá se a mulher estiver em seu período fértil, poderíamos tender a considerá-la incompleta ou errada. Contudo, um olhar mais atento fornece indicações de como os alunos estariam compreendendo a reprodução, em que a partir da menarca em qualquer época do mês a menina (ou mulher) está correndo o risco de engravidar, sem exceção.

De acordo com essa elaboração dos alunos, a gravidez é um risco que se assume quando se inicia a vida sexual, e que, tal como destacou Leal, ${ }^{10}$ transforma-se em "um evento que pode vir a ocorrer ou não e que está sempre sujeito a um universo de possibilidades aleatórias”. Depreende-se que a preocupação com as DSTs figura como secundária não só nos discursos dos alunos, como de fato se confirma na prática, quando os jovens sugerem preferir assumir o risco da gravidez ao sacrifício do prazer sexual, resistindo à adesão aos métodos contraceptivos.

O sangue, além de aparecer como um sinal de fertilidade, também figura como um sinal corpóreo da "perda da virgindade", com forte simbolismo em especial para os meninos. A noção de que o rompimento do hímen provoca necessariamente sangramento na mulher, e por vezes no homem, é concebido como a prova da virgindade feminina, sendo, portanto, desejável 
que ocorra. Os menos iniciados e mais iniciados, ao questionarem "Quando perdermos nossa virgindade vai sangrar?”, articularam suas próprias percepções ao discurso da revista Capricho: "Sim. Porque acontecem pequenos ferimentos que ocorrem durante a penetração, principalmente se estiver tensa e com pouca lubrificação", segundo a elaboração dos alunos(as) menos iniciados. E, complementarmente, da revista Atrevida os mesmos utilizaram o seguinte trecho, publicado na edição de junho de 2011:23

Sou virgem, mas algumas vezes meu namorado colocou o dedo na minha vagina. Sempre gostei, mas depois de um tempo, começou a doer e a sair um corrimento marrom [...] Desde então, não deixo mais o meu namorado fazer isso. Será que o meu hímen está se rompendo aos poucos? Resposta: O fato de seu namorado ter introduzido o pênis na sua vagina pode ter causado o rompimento do seu himen [...] No entanto, não dê tanta importância a este acontecimento. Você praticamente já tinha uma vida sexual com seu namorado, afinal, não há muita diferença entre um dedo e o pênis, se pensarmos em intimidade.

A ideia de que durante a penetração podem ocorrer pequenos ferimentos na vagina da mulher se justifica por tensão feminina e falta de lubrificação. Percebe-se que essa resposta elaborada pelos alunos aparece influenciada por uma ofertada por Atrevida a outra pergunta enviada à revista, e que foi reaproveitada pelos alunos em outro contexto. Os alunos atribuíram outro sentido não só ao texto extraído da revista, como também apresentaram uma noção distinta das anteriores, explicando que o rompimento do hímen causaria ferimentos na vagina, por isso há o sangramento.

Os meninos mais iniciados mencionaram que a primeira relação sexual também pode provocar sangramentos neles, mas pelo ímpeto no ato sexual e não por qualquer fragilidade masculina, como é atribuído ao caso da mulher, em que palavras que denotam a fragilidade feminina foram usadas, tais como "pouca" ou "tensa”. Martin salienta o uso de termos de conotação negativa sobre os processos corporais na reprodução feminina, haja vista que a presença de sangue na primeira relação sexual adquire significados bem diferentes para meninos e meninas. ${ }^{24}$ Nos homens, o sangramento sugere o vigor e a virilidade masculina no ato sexual; nas mulheres, o sangramento, embora também apareça como desejável, sugere uma suscetibilidade feminina na prática sexual.

\section{Considerações finais}

O uso das revistas entre os escolares revelou questionamentos contundentes entre jovens sobre os modos de expressão de modelos e estereótipos de masculinidade e feminilidade. As relações de gênero mostraram-se mais sistematicamente problematizadas, sendo o papel feminino nos relacionamentos, os preconceitos e os estereótipos questionados em alguns momentos pelos escolares, ainda que se observe uma naturalização na percepção acerca das desigualdades de gênero refletidas na saúde sexual e reprodutiva. 
Pode-se observar aproximações entre as representações corporais produzidas pelos jovens da pesquisa e o público leitor das revistas que tiveram suas dúvidas publicadas. Nessa comparação, as dúvidas formuladas pelos alunos mais e os menos iniciados permitiu concluir que as revistas Capricho e Atrevida atenderam algumas das demandas dos escolares. Contudo, há um descompasso entre os discursos e imagens produzidas sobre essas dúvidas nas revistas e a experiência subjetiva dos jovens, uma vez que não aprofundam os assuntos de seu interesse e as lacunas na construção do conhecimento por eles agenciado permanecem.

Tais lacunas são especialmente observadas nas questões que versam sobre reprodução, relacionamentos afetivos e a primeira relação sexual. Isto sugere, na relação dos jovens com as revistas, uma participação relativa dessas publicações em meio às redes comunicativas, na construção das identidades sexuais. Em um cenário sociopolítico em transformação, no que se refere aos direitos sexuais e reprodutivos, as revistas femininas juvenis demonstraram estar aquém das discussões sociais sobre o tema e das atuais demandas dos jovens.

Conforme apresentado, as revistas, muitas vezes citadas pelos jovens como fonte de informação para a entrada na sexualidade com um parceiro, despertaram muitos questionamentos e críticas. Nos modos de entrada na sexualidade, quanto aos usos que os jovens fazem dos meios de comunicação, destaca-se o repertório mais abrangente mencionado pelos meninos mais iniciados e os menos iniciados, ao creditarem maior aprendizado por meio das revistas do gênero de Playboy e Sexy, filmes pornográficos e internet.

Na perspectiva das relações de gênero houve a observação, por parte dos meninos, de que as revistas e materiais a eles direcionados contemplem de modo mais acentuado o universo masculino, uma vez que prevalecem assuntos de interesse das jovens. Em continuidade, os meninos reivindicaram serem retratados de forma "mais realista" nas revistas e mais próxima das experiências por eles vividas, sugerindo mudanças em curso na experiência da sexualidade e da identidade masculina.

Tendo em vista a necessidade de refletir sobre as práticas educativas em saúde sexual e reprodutiva, cabe destacar o uso de metodologias participativas que considerem os conhecimentos prévios dos jovens para abordar o tema da sexualidade, em concordância com o Manual de Atenção Básica do Ministério da Saúde. ${ }^{1}$ Nessa direção, a linguagem empregada pelas revistas femininas juvenis, ao produzir identificações dos jovens com alguns dos temas acerca da sexualidade, favorece seu uso em abordagens educativas junto aos jovens. A leitura crítica que os jovens fazem deste meio de comunicação, no entanto, extrapola os endereçamentos contidos nessas publicações, o que pode ser incorporado pela ação educativa em saúde sexual e reprodutiva.

A percepção ampliada dos jovens quanto à experiência da sexualidade mostra alguns pontos críticos da abordagem desse tema no âmbito escolar, tendo em vista as proposições no plano das políticas públicas de saúde voltadas à garantia dos direitos sexuais e reprodutivos. Uma discussão 
política quanto à temática da diversidade sexual para a formulação de estratégias educativas em sala de aula, sobretudo, apresenta-se como um desafio entre os docentes/educadores. A invisibilidade desse tema no âmbito escolar pode também ser identificada em determinados meios de comunicação, como nos mostra a leitura dos jovens sobre as revistas de circulação nacional.

De acordo com o Manual de Atenção Básica do Ministério da Saúde, ${ }^{1}$ faz-se necessário considerar que as ações integradas para a promoção da saúde sexual e reprodutiva, seja na escola ou através dos serviços de saúde, preconizam "uma compreensão mais abrangente do ser humano e do processo saúde-doença, entendendo esse processo como complexo, não podendo ser reduzido somente à dimensão biológica". Compreendemos, por fim, que os avanços no reconhecimento dos direitos sexuais e reprodutivos - por exemplo, o recente reconhecimento legal, pelo Poder Judiciário, da união homoafetiva - não garantem por si só a implementação de ações e estratégias educativas efetivas entre os jovens. Reflexões sobre "como fazer" ainda são pouco problematizadas na escola e nos serviços de saúde.

\section{Referências}

1. Brasil. Ministério da Saúde. Normas e manuais técnicos. Brasília: Ministério da Saúde; 2010. Cadernos de Atenção Básica, 26.

2. Ferreira FR. A produção de sentidos sobre a imagem do corpo. Interface - Comunic. Saúde, Educ. 2008; 12(26):471-483.

3. Rios LF. Quando o assunto é cultura sexual: um "olhar sobre a mídia”. In: Comissão de Cidadania e Reprodução. Olhar sobre a mídia. Belo Horizonte: Mazza; 2002. p. 109-146.

4. Fischer RMB. O dispositivo pedagógico da mídia: modos de educar na (e pela) TV. Educação e Pesquisa 2002; 28(1):151-162.

5. Minayo MCS. O Desafio do conhecimento: pesquisa qualitativa em saúde. São Paulo: Hucitec; 2010. $407 \mathrm{p}$.

6. Foote-Whyte W. Treinando a observação participante. In: Zaluar A, organizadora. Desvendando máscaras sociais. São Paulo: Francisco Alves; 1980. p. 77-86.

7. Victora CG, Knauth DR, Hassen MNA. A pesquisa qualitativa em saúde: uma introdução ao tema. Porto Alegre: Tomo Editorial; 2000.

8. Martin-Barbero J. América Latina e os anos recentes: o estudo da recepção em comunicação social. In: Souza MW, organizador. Sujeito, o lado oculto do receptor. São Paulo. Brasiliense; 1995. p. 39-70.

9. Souza ER. Marcadores sociais da diferença e infância: relações de poder no contexto escolar. Cad. Pagu 2006; 26:169-199.

10. Leal OF. Sangue, fertilidade e práticas contraceptivas. In: Leal OF. Corpo e significado: ensaios de antropologia social. Porto Alegre: Editora da UFRG; 1995. p. 13-35. 
11. Geertz C. Uma descrição densa: por uma teoria interpretativa da cultura. In: Geertz C. A Interpretação das culturas. Rio de Janeiro: Zahar; 1989. p. 13-41.

12. Matta R. Relativizando: uma introdução à antropologia social. Rio de Janeiro: Rocco; 1993.

13. Mira MC. O leitor e banca de revistas: a segmentação da cultura no século XX. São Paulo: Olho d'Água-FAPESP; 2001.

14. Freire Filho J. Em cartaz, as garotas superpoderosas: a construção discursiva da adolescência feminina na revista Capricho. Revistas Fronteiras-Estudos Midiáticos 2006; 8(2):102-111.

15. Heilborn ML. Entre as tramas da sexualidade brasileira. Revista Estudos Feministas 2006; 14(1):43-59.

16. Heilborn ML, Cabral CS, Bozon M. Valores sobre sexualidade e elenco de práticas: tensões entre modernização diferencial e lógicas tradicionais. In: Heilborn ML, Aquino EML, Bozon M, Knauth $\mathrm{DR}$, organizadores. O aprendizado da sexualidade: reprodução e trajetórias sociais de jovens brasileiros. Rio de Janeiro: Fiocruz; 2006. p. 207-266.

17. Revista Capricho maio 2011; (1122)

18. Louro GL. A construção escolar da diferença. In: Louro GL. Gênero, sexualidade e educação: uma perspectiva pós-estruturalista. Petrópolis: Vozes; 1997. p. 57-87.

19. Revista Atrevida mar. 2011; (199).

20. Bozon M, Heilborn ML. As carícias e as palavras. Iniciação sexual no Rio de Janeiro e em Paris. Novos Estudos CEPRAB, mar. 2001; 59:111-35.

21. Britzman D. Curiosidades, sexualidade e currículo. In: Louro GL, organizador. O corpo educado: pedagogias da sexualidade. $3^{\text {a }}$ ed. Belo Horizonte: Autêntica; 2010. p. 83-112.

22. Sousa MW. Recepção e comunicação: a busca do sujeito. In Sousa MW, organizador. Sujeito, o lado oculto do receptor. São Paulo: Brasiliense; 1995. p. 13-38.

23. Revista Atrevida jun. 2011; (202).

24. Martin E. A mulher no corpo: uma análise cultural da reprodução. Rio de Janeiro: Garamound; 2006.

Recebido: 29/3/2016

Revisado: 29/7/2016

Aceito: 25/8/2016 